\title{
The use of deep brain stimulation in Tourette's syndrome
}

\author{
Janine Rotsides, B.S., ANd Antonios Mammis, M.D. \\ Department of Neurological Surgery, Rutgers New Jersey Medical School, Newark, New Jersey
}

\begin{abstract}
Tourette's syndrome (TS) is a childhood neuropsychiatric disorder characterized by multiple involuntary motor and vocal tics. It is commonly associated with other behavioral disorders including attention-deficit/hyperactivity disorder, obsessive-compulsive disorder, anxiety, depression, and self-injurious behaviors. Tourette's syndrome can be effectively managed with psychobehavioral and pharmacological treatments, and many patients experience an improvement in tics in adulthood. However, symptoms may persist and cause severe impairment in a small subset of patients despite available therapies. In recent years, deep brain stimulation (DBS) has been shown to be a promising treatment option for such patients. Since the advent of its use in 1999, multiple targets have been identified in DBS for TS, including the medial thalamus, globus pallidus internus, globus pallidus externus, anterior limb of the internal capsule/nucleus accumbens, and subthalamic nucleus. While the medial thalamus is the most commonly reported trajectory, the optimal surgical target for TS is still a topic of much debate. This paper provides a review of the available literature regarding the use of DBS for TS.

(http://thejns.org/doi/abs/10.3171/2013.8.FOCUS13292)
\end{abstract}

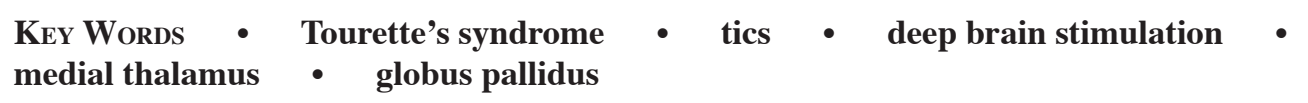

I N 1885, Georges Gilles de la Tourette described 9 patients who suffered from "a neurological condition characterized by motor incoordination accompanied by echolalia and coprolalia." 30 Charcot later named the condition Tourette's syndrome (TS). ${ }^{30}$ Tourette's syndrome is a complex childhood neuropsychiatric disorder characterized chiefly by the presence of tics. Tics are sudden, involuntary, repetitive muscle contractions (motor tics) or phonic productions (vocal tics). Tics are usually preceded by premonitory sensory urges with feelings of relief after execution of the tic. ${ }^{31}$ Once thought to be rare, recent studies suggest that TS is more common than previously believed. The prevalence of TS differs among studies due to variations in age, sex, diagnostic criteria, and assessment methods, but is estimated at $0.77 \%$ in children and is considered to be 4 times more common in males than in females. ${ }^{28}$

Symptoms of TS typically develop during the 1st de-

Abbreviations used in this paper: ADHD = attention-deficit/ hyperactivity disorder; ALIC $=$ anterior limb of the internal capsule; $\mathrm{BDI}=$ Beck Depression Inventory; $\mathrm{CM}=$ centromedian; $\mathrm{DBS}=$ deep brain stimulation; $\mathrm{GPe}=$ globus pallidus externus; $\mathrm{GPi}=$ globus pallidus internus; $\mathrm{NA}=$ nucleus accumbens; $\mathrm{OCD}=$ obsessivecompulsive disorder; $\mathrm{PD}=$ Parkinson's disease; $\mathrm{Pf}=$ parafascicular; $\mathrm{Spv}=$ substantia periventricularis; STAI $=$ State-Trait Anxiety Inventory; TS = Tourette's syndrome; Voi = ventral oral internal; YBOCS = Yale-Brown Obsessive Compulsive Scale; YGTSS = Yale Global Tic Severity Scale.

cade of life, with a mean age of onset of 7 years. Initial symptoms commonly manifest as simple motor tics of the head and face, with vocal tics appearing 1-2 years later. ${ }^{31}$ Motor tics can be characterized as abrupt in onset, fast, and brief (clonic) or slow and sustained (dystonic or tonic). Simple tics involve only a single muscle or group of muscles, such as eye blinking, grimacing, sniffing, or throat clearing, while complex tics involve the coordinated action of multiple muscles to produce seemingly voluntary motor movements; examples include throwing, hitting, head shaking, or uttering phrases. ${ }^{25}$ Symptoms wax and wane throughout its course, with tics changing in character, frequency, and location over time. Tics typically become more frequent and severe during periods of excitement, stress, or fatigue or when the patient is alone. On the other hand, tics may improve during times of relaxation and selective attention. ${ }^{10}$ It has been reported that tics can be voluntarily suppressed for brief periods of time, but results in increased inner tension and a rebound period. ${ }^{18}$ Patients with TS typically experience worsening symptoms during prepubescent years, peaking around age 10, with improvement during adolescence. An estimated 59\%-85\% of patients with TS experience a decline in the severity and number of tics in adulthood. ${ }^{21}$ Complete remission of tics in adulthood has also been documented in several studies. ${ }^{8,43}$

A diagnosis of TS is based on clinical evaluation. Diagnostic criteria for TS, as outlined in the Diagnostic and 
Statistical Manual of Mental Disorders-IV, ${ }^{3}$ require the presence of both multiple motor tics and 1 or more vocal tics, not necessarily simultaneously. Symptoms must develop before the age of 18 years and tics must occur multiple times per day nearly every day or intermittently for at least 1 year, with no more than 3 consecutive tic-free months. The tics must not be due to the direct physiological effects of a substance or general medical condition. ${ }^{3}$ Other than the presence of tics, the neurological examination is typically normal. Currently, there are no laboratory tests or imaging studies that can definitively diagnose TS, but these may be useful in ruling out other diseases. ${ }^{57}$

Tourette's syndrome is frequently associated with other psychiatric disorders. Attention-deficit/hyperactivity disorder (ADHD) is the most common comorbidity, found in $21 \%-90 \%$ of TS patients. Obsessive-compulsive disorder has been reported in $11 \%-80 \%$ of TS patients, and self-injurious behavior is found in approximately $33 \%$ of TS patients. Other psychiatric comorbidities include anxiety, depression, and personality disorders. ${ }^{47}$ The severity of tics and psychiatric disorders, and their impact on the life of patients with TS, ranges from mild to severe. Higher tic severity is generally associated with greater functional impairment. ${ }^{12}$ However, psychiatric and behavioral symptoms may be more problematic and have a greater impact on quality of life than tics. ${ }^{16}$

Much of the pathophysiology of TS still remains unclear, but dysfunction of the basal ganglia and parallel striatal-thalamic-cortical circuits are believed to play a major role in the disorder..$^{19}$ The striatum and subthalamic nucleus receive excitatory input from the cortex and serve as the major inputs to the basal ganglia. The globus pallidus internus (GPi) and the substantia nigra pars reticulata serve as the major output, with inhibitory projections to the thalamus and midbrain that modulate motor patterns of the cerebral cortex and brainstem. ${ }^{40}$ Inappropriate activation of striatal neurons with inhibitory projections to the GPi and substantia nigra pars reticulata have been suggested in TS. Abnormal inhibition of the GPi and substantia nigra pars reticulata can lead to increased thalamocortical drive, resulting in unwanted motor patterns and the execution of tics. ${ }^{39}$ Aberrant action of dopamine has also been implicated in the pathophysiology of TS. Dopamine-mediated long-term potentiation of striatal neurons can cause excessive activity modulating cortical-striatal transmission. ${ }^{40}$ This theory is supported, in part, by the relative efficacy of neuroleptics in treating TS. ${ }^{25}$ Dysfunction in excitatory thalamostriatal loops are also believed to play a role. These loops involve the centromedian-parafascicular (CM-Pf) complex of the thalamus and project to the motor striatum and midline thalamic nuclei (substantia periventricularis $[\mathrm{Spv}])$, toward the limbic part of the striatum. ${ }^{50}$

Due to its complex and variable clinical presentation, a multifactorial approach is often taken in the treatment of TS. It is important to assess the individual needs of the patient and treat the most debilitating symptoms. In patients with milder forms of TS, psychobehavioral therapy is often an effective form of treatment and aims to teach patients how to control environmental factors that affect their tics. These therapies include relaxation training, $\operatorname{cog}$ nitive behavioral therapy, habit reversal training, and com- prehensive behavioral intervention for tics ${ }^{56}$ For patients with moderate to severe TS, pharmacological treatment may be necessary. Standard tic-suppressing medications include $\alpha_{2}$-adrenergic agonists, typical and atypical neuroleptics, benzodiazepines, and botulinum toxin injections into muscle groups responsible for debilitating tics. ${ }^{38,56} \mathrm{In}$ some cases, symptoms of associated behavioral disorders can be more debilitating than tics and must be treated. ${ }^{16}$ Despite previous conceptions that stimulant medications for ADHD can worsen tics, recent evidence suggests that methylphenidate, $\alpha_{2}$ agonists, desipramine, and atomoxetine can effectively treat patients with TS and ADHD without worsening tics. ${ }^{7}$ Comorbid obsessive-compulsive disorder (OCD) can be treated with cognitive behavioral therapy, selective serotonin reuptake inhibitors (SSRIs), and typical and atypical neuroleptics. ${ }^{38}$ Despite available behavioral and pharmacological treatments, there is a small subset of patients with TS who fail to show clinical improvement or experience potentially life-threatening tics or self-injurious behavior ("malignant TS"). ${ }^{11}$ If symptoms remain severe and cause marked impairment in functioning, surgical intervention may be warranted.

\section{An Overview of Surgery for TS}

Baker ${ }^{5}$ described what is believed to be the first neurosurgical procedure for TS, in a 22-year-old patient suffering from somatomotor and vocal tics since the age of 9. Other clinical symptoms included severe panic attacks with depersonalization and feelings of hopelessness. Pharmacological treatment showed no efficacy in improving tics or behavioral symptoms. In 1960, a bimedial leucotomy was performed, which resulted in significant reduction in tic severity and panic attacks following the procedure and at 1-year follow-up. Since then, there have been more than 24 reports of ablative surgery for treatment-refractory TS in more than 60 patients. These cases have been described in detail and include: prefrontal lobotomy; bimedial frontal leucotomy; limbic leucotomy; anterior cingulotomy; lesions of the medial, intralaminar and ventrolateral thalamic nuclei; lesions of the zona incerta; lesions of the red nucleus; and dentatotomy. Unfortunately, most of these procedures yielded disappointing results or produced adverse side effects, such as hemiplegia and dystonia..$^{58}$

In 1999, deep brain stimulation (DBS) for intractable TS was introduced by Vandewalle et al. ${ }^{60}$ Bilateral stimulation of the medial thalamus at the cross-point of the CM and ventral oral internal (Voi) thalamic nuclei and the Spv was performed in a single patient. This target mimicked the trajectory of Hassler and Dieckmann, ${ }^{22}$ who performed bilateral ablation of the intralaminar and medial thalamic nuclei in 9 patients. Three of the 9 patients reported $70 \%-100 \%$ reduction in their tics. Vandewalle et al.$^{60}$ revealed similar results at 1-year follow-up, with almost complete abolition of tics.

\section{Deep Brain Stimulation Targets}

Since 1999, reports of DBS for refractory TS have continued to surface, but are sparse, and the procedure is still considered experimental. Based on the developing pathophysiology of TS, 5 DBS targets have been identi- 


\section{Deep brain stimulation for Tourette's syndrome}

fied: the medial thalamus, , $2,4,26,33,45,46,51-53,55,60,61 \mathrm{GPi}^{9,13-15}$, 23,36,54,59,62 globus pallidus externus (GPe), ${ }^{44}$ anterior limb of the internal capsule (ALIC)/nucleus accumbens (NA), ${ }^{17,29,41,49,63}$ and the subthalamic nucleus. ${ }^{37}$ While the medial thalamus has been the most widely reported DBS target, there is still much debate over which target provides optimal results. This paper provides a review of available literature regarding the use of DBS to treat TS.

\section{Medial Thalamus}

Visser-Vandewalle et al. ${ }^{61}$ published a second report on 3 patients who received bilateral stimulation of the CM and Voi thalamic nuclei and the Spv (Table 1). All of the patients had experienced severe and impairing tics since childhood, with minimal relief from pharmacological or alternative treatments. The authors reported a $90.1 \%$ tic reduction after 5 years in Patient 1 , a $72.2 \%$ tic reduction after 1 year in Patient 2, and an $82.6 \%$ tic reduction after 8 months in Patient 3. The authors conducted a followup study to assess the long-term effects of DBS in these patients. ${ }^{1}$ At the 10 -year follow-up, Patient 1 continued to experience a significant reduction in tics (92.6\%). At the 6-year follow-up, a $78 \%$ reduction in tics was reported for Patient 3. Patient 2 was lost to follow-up. Patients 1 and 3 reported side effects of decreased energy and changes in sexual functioning.

In 2007, Bajwa et al. ${ }^{4}$ published a case report on a single patient who underwent DBS for chronic, severe TS. Trajectory included the CM and Voi thalamic nuclei and the Spv. At 24 months' follow-up, a $66 \%$ reduction in tics was reported.

Later in 2007, Maciunas et al. ${ }^{35}$ published a prospective, randomized, double-blind trial of bilateral thalamic stimulation in 5 patients with TS. Electrodes were implanted at the anterior extent of the CM-Pf complex. Patients were randomized and evaluated in 1 of 4 states of unilateral or bilateral stimulation (both stimulators on, left on/right off, right on/left off, both off) for 1 week each. A subsequent open-label evaluation with 3 months' follow-up was conducted. There was a mean $53 \%$ reduction in motor tics with both stimulators on, but no reported benefit from unilateral stimulation. Three of the 5 patients showed a statistically significant reduction in motor and vocal tics at all points of evaluation. At final follow-up, a mean $44 \%$ reduction in tics was observed.

Servello et al. ${ }^{52}$ published a case series of 18 patients treated with DBS for treatment-refractory TS in 2008. Bilateral stimulation of the CM-Pf and Voi thalamic nuclei was chosen for all patients and patient follow-up ranged from 3 to 18 months. All patients responded well to DBS and reported a reduction in the number of tics, but 12 patients continued to experience tics and required multiple adjustments to the stimulation parameters. Furthermore, 4 patients reported unsatisfactory results after 3-6 months of follow-up. Nine months after the initial procedure, a blinded "on-off" evaluation was performed in 9 patients. Eight patients experienced worsening symptoms in the "off" condition.

\section{TABLE 1: Thalamic targets of DBS for TS*}

\begin{tabular}{|c|c|c|c|c|}
\hline Authors \& Year & No. of Patients & Target & Follow-Up & Outcome \\
\hline Visser-Vandewalle et al., 2003 & 3 & CM-Voi-Spv & $\begin{array}{l}\text { patient 1: } 5 \mathrm{yrs} \\
\text { patient 2: } 1 \mathrm{yr} \\
\text { patient 3: } 8 \mathrm{mos}\end{array}$ & $\begin{array}{l}\text { reduction in tic scores: } 90.1 \% \text { (patient 1), } 72.2 \% \text { (patient 2), } \\
\quad 82.6 \% \text { (patient 3) }\end{array}$ \\
\hline Bajwa et al., 2007 & 1 & CM-Voi-Spv & $2 \mathrm{yrs}$ & $66 \%$ reduction in tic score \\
\hline Maciunas et al., 2007 & 5 & CM-Pf & $3 \mathrm{mos}$ & mean $44 \%$ tic reduction \\
\hline Servello et al., 2008 & 18 & CM-Pf-Voi & $3-18 \mathrm{mos}$ & mean $28.6 \%$ tic reduction \\
\hline Shields et al., 2008 & 1 & CM-Pf-Voi & $3 \mathrm{mos}$ & $41 \%$ reduction in tic score, $50 \%$ reduction in overall impairment \\
\hline Porta et al., 2009 & 15 & CM-Pf-Voa & $2 \mathrm{yrs}$ & $\begin{array}{l}\text { score reductions: } \\
76.5 \text { to } 36.6 \text { (YGTSS) } \\
20.9 \text { to } 14.4 \text { (YBOCS) } \\
30.7 \text { to } 22.7 \text { (BDI) } \\
44.2 \text { to } 29.5 \text { (STAI) }\end{array}$ \\
\hline Servello et al., 2010 & 19 & CM-Pf-Voi & $2 \mathrm{yrs}$ & $\begin{array}{l}\text { score reductions: } \\
75.5 \text { to } 40 \text { (YGTSS) } \\
19.6 \text { to } 16.3 \text { (YBOCS) } \\
26.2 \text { to } 17.7 \text { (BDI) } \\
45.8 \text { to } 31.3 \text { (STAI) }\end{array}$ \\
\hline Ackermans et al., 2010 & 2 & CM-Voi-Spv & $\begin{array}{l}\text { patient } 1: 10 \mathrm{yrs} \\
\text { patient 2: } 6 \text { yrs }\end{array}$ & reduction in tic scores: $92.6 \%$ (patient 1), $78 \%$ (patient 2) \\
\hline Ackermans et al., 2011 & 6 & CM-Voi-Spv & $1 \mathrm{yr}$ & mean $49 \%$ improvement in tic severity \\
\hline Kaido et al., 2011 & 3 & CM-Pf-Voi & $1 \mathrm{yr}$ & $55 \%-70 \%$ decrease in YGTSS score \\
\hline Pullen et al., 2011 & 1 & CM-Pf & $18 \mathrm{mos}$ & reduction in YGTSS score from 77 to 14 \\
\hline Lee et al., 2011 & 1 & CM-Pf & $6 \mathrm{mos}$ & $62 \%$ decrease in tic severity \\
\hline Savica et al., 2012 & 3 & CM-Pf & $1 \mathrm{yr}$ & $70 \%$ reduction in tics, $78 \%$ improvement in overall impairment \\
\hline
\end{tabular}

* Voa $=$ ventral oral anterior. 


\section{J. Rotsides and A. Mammis}

Shields et al. ${ }^{55}$ performed a within-subject comparison of DBS for treatment-refractory TS. Electrodes were originally placed at the ALIC-NA, and at the 18-month follow-up there was a $21 \%$ reduction in total tic score and $25 \%$ reduction in overall impairment. Mild side effects included apathy, depressed mood, and hypomania. Due to device complications, the electrodes needed to be reimplanted and the patient opted for placement at the CM-Pf-Voi thalamic nuclei. When compared with baseline scores, the authors now reported a $41 \%$ reduction in total tic score and $50 \%$ reduction in overall impairment, 3 months after the second surgery.

Porta et al. ${ }^{45}$ reported on the long-term follow-up of 18 patients who received bilateral thalamic stimulation of the CM-Pf and ventral oral anterior thalamic nuclei. Two patients withdrew from the study and 1 needed further DBS surgery targeting the GPi. Therefore, only 15 patients were evaluated during a 2-year follow-up period. At 24 months, there was a reduction in global tic severity in all patients and a reduction in social impairment in 14 patients. Furthermore, there was a statistically significant decrease in reported depression, anxiety, and obsessivecompulsive symptoms.

One of the largest studies on DBS for TS was conducted by Servello et al. ${ }^{53}$ The goal was to find a "common target" for both tics and behavioral comorbidities. Beginning in 2004, 36 patients were selected and underwent a collective 76 procedures. The specific target for each surgery was chosen based on clinical presentation of the individual patient: 67 procedures targeted the CMPf-Voi complex of the thalamus; 2 procedures targeted the posterior GPi. This trajectory was chosen to address dystonic tics in the patient. Ten procedures, in a total of 5 patients, targeted the ALIC-NA. This procedure was performed as a second "rescue surgery" for severe comorbidity in 4 of the 5 patients, despite a decrease in tic severity and frequency after the initial DBS surgery. A single patient received stimulation of the ALIC-NA alone. Electrodes were implanted bilaterally in all but 1 patient, who received unilateral stimulation of the right CM-PfVoi. Two-year follow-up was reached for 22 patients, 3 of whom turned off their devices and were excluded from analysis. The remaining 19 patients received stimulation of the CM-Pf-Voi and showed significant improvement in the Yale Global Tic Severity Scale (YGTSS), ${ }^{32}$ YaleBrown Obsessive Compulsive Scale (YBOCS), ${ }^{48}$ Beck Depression Inventory (BDI) ${ }^{6}$ and the State-Trait Anxiety Inventory (STAI). ${ }^{27}$

More recently, Ackermans et al. ${ }^{2}$ conducted a randomized, double-blind cross-over trial of 6 patients who received bilateral stimulation targeting the CM-Voi-Spv. Patients were randomly assigned to either have a stimulation-on period after surgery for 3 months, followed by stimulation-off period for 3 months (Group A) or vice versa (Group B). Following the crossover period, stimulators were switched on for 6 months. Primary outcome was tic severity, measured using the total YGTSS score, and secondary outcome was change in associated behavioral disorders and mood. Tic severity at the end of the stimulation-on period was significantly $(37 \%)$ lower than at the end of the stimulation-off period. Significant im- provement in tic severity from baseline (49\%) was sustained at 1-year follow-up. No significant changes in behavioral disorders and mood were observed between on and off conditions or at 1-year follow-up.

Case reports continue to be published and provide further evidence for the effectiveness of DBS in treating TS. Kaido et al. ${ }^{26}$ reported on an open-label case series study describing 3 patients who received DBS for severe, self-injuring TS. Electrodes were implanted at the CMPf-Voi of the thalamus and patients were evaluated at 1,3 , 6 , and 12 months after surgery. In all patients, there was a significant decrease in YGTSS scores, total tic scores, and social impairment at all points of follow-up. The severity of OCD symptoms decreased in 2 patients, but increased in the other patient. The only reported side effect was blurred vision, which resolved when stimulation amplitude was lowered.

Pullen et al. ${ }^{46}$ described a 17 -year-old patient with worsening intractable TS, OCD, and ADHD, who received bilateral stimulation of CM-Pf complex. The surgery resulted in a significant improvement in tic severity and psychosocial functioning at the 18-month followup. Additionally, Lee et al. ${ }^{33}$ reported on a patient with chronic, intractable TS with worsening tics at the age of 30. Electrodes were implanted at the CM-Pf complex and a reduction in tics was observed immediately following surgery. Tics reappeared 1 week later and persisted even after the stimulator was switched on. Voltage was gradually increased until the patient reported significant improvement in his tics after 6 weeks. At 6-months followup, there was a $62 \%$ improvement in tics, which remained stable 18 months after surgery.

In 2012, Savica et al. ${ }^{51}$ reported on the 1-year followup of 3 patients who underwent DBS for debilitating, treatment-refractory TS and comorbid OCD and ADHD. The CM-Pf complex was targeted, bilaterally. A mean $70 \%$ reduction in tic severity and $78 \%$ improvement in overall impairment was reported.

\section{Globus Pallidus}

The posteroventral GPi, anteromedial GPi, and globus pallidus externus (GPe) have all been targeted in DBS for TS. However, the number of studies regarding these targets and the sample sizes used remain small. The effects of bilateral stimulation of the posteroventral GPi were first described by Van der Linden et al. ${ }^{59}$ in 2002 (Table 2). A 95\% reduction in tics was observed at the 6-month follow-up in a single patient.

In 2005, Diederich et al. ${ }^{15}$ reported on the 14-month follow-up of a 27-year-old patient suffering from treatment-refractory TS and compulsive tendencies that caused profound social impairment and secondary depression. The posteroventral GPi was targeted during DBS and an improvement in tics was observed progressively in the months following surgery. There was a reported $73 \%$ reduction in tic frequency. The patient also reported a decrease in the internal urge to produce tics. When the stimulator was switched off for 48 hours during follow-up, a $66 \%$ increase in tic frequency was observed. There was no change in compulsions, but a reduction in depression and anxiety were reported. 
Deep brain stimulation for Tourette's syndrome

TABLE 2: Pallidal targets of DBS for TS

\begin{tabular}{|c|c|c|c|c|}
\hline Authors \& Year & $\begin{array}{l}\text { No. of } \\
\text { Patients }\end{array}$ & Target & Follow-Up & Outcome \\
\hline Van der Linden et al., 2002 & 1 & posteroventral GPi & $6 \mathrm{mos}$ & $95 \%$ tic reduction \\
\hline Diederich et al., 2005 & 1 & posteroventral GPi & $14 \mathrm{mos}$ & $\begin{array}{l}\text { 73\% decrease in tic frequency; score reductions: } 8 \text { to } 2 \\
\text { (BDI), } 66 \text { to } 40 \text { (STAI) }\end{array}$ \\
\hline Houeto et al., 2005 & 1 & $\begin{array}{l}\text { anteromedial GPi/ } \\
\text { thalamus (CM-Pf) }\end{array}$ & $\begin{array}{l}2 \text { mos for each condi- } \\
\text { tion, } 2 \text { yrs total }\end{array}$ & $\begin{array}{l}65 \% \text { tic reduction (CM-Pf), } 65 \% \text { decrease in tics (Gpi); final } \\
\text { evaluation: remained improved, } 70 \% \text { tic reduction }\end{array}$ \\
\hline Shahed et al., 2007 & 1 & posteroventral GPi & $6 \mathrm{mos}$ & $84 \%$ tic reduction, $69 \%$ improvement in OCD symptoms \\
\hline Welter et al., 2008 & 3 & $\begin{array}{l}\text { anteromedial GPi/ } \\
\text { thalamus (CM-Pf) }\end{array}$ & $\begin{array}{l}\text { patient 1: } 60 \mathrm{mos} \\
\text { patient 2: } 27 \mathrm{mos} \\
\text { patient 3: } 20 \mathrm{mos}\end{array}$ & $\begin{array}{l}82 \% \text { reduction in tics } w / \text { combined stimulation, stable re- } \\
\text { duction in tics } w / \text { pallidal stimulation, } 74 \% \text { reduction in } \\
\text { tics } w / \text { combined stimulation }\end{array}$ \\
\hline Dehning et al., 2008 & 1 & posteroventral GPi & $1 \mathrm{yr}$ & reduction in YGTSS score from 83 to 10 \\
\hline Martínez-Fernández et al., 2011 & 5 & $\begin{array}{l}\text { posteroventral GPi; } \\
\text { anteromedial GPi }\end{array}$ & $3-24$ mos & $\begin{array}{l}29 \% \text { improvement in tics, } 26 \% \text { improvement in YBOCS } \\
\text { score, } 54.4 \% \text { improvement in reported quality of life }\end{array}$ \\
\hline Dehning et al., 2011 & 3 & posteroventral GPi & $1 \mathrm{yr}$ & $\begin{array}{l}\text { patient } 1: 17 \% \text { tic reduction } \\
\text { patient 2: no benefit } \\
\text { patient } 3: 64 \% \text { decrease in tic severity }\end{array}$ \\
\hline Cannon et al., 2012 & 11 & anteromedial GPi & $4-30$ mos & $\begin{array}{l}49.6 \% \text { decrease in total tic severity, } 59 \% \text { decrease in OCD } \\
\text { symptoms }\end{array}$ \\
\hline Piedimonte et al., 2013 & 1 & $\mathrm{GPe}$ & $6 \mathrm{mos}$ & $\begin{array}{l}\text { 70.5\% tic reduction, improvement in anxiety, depression, \& } \\
\text { global functioning }\end{array}$ \\
\hline
\end{tabular}

In the same year, Houeto et al. ${ }^{23}$ conducted a prospective, randomized, double-blind study using a single patient with intractable TS and self-injurious behaviors. The goal was to determine if there was an observed difference in benefits from using different targets or with multiple targets used in combination. Deep brain stimulation electrodes were implanted bilaterally at the CMPf complex of the thalamus and the anteromedial GPi. The patient was randomized into 1 of 5 conditions (no stimulation, thalamic stimulation alone, pallidal stimulation alone, sham stimulation, and combined thalamic and pallidal stimulation). Two months after thalamic stimulation was started, there was a $65 \%$ decrease in tic severity, disappearance of self-injurious behaviors, and an improvement in mood, anxiety, and impulsivity. Pallidal stimulation also resulted in a $65 \%$ decrease in tic severity, but coprolalia persisted. Self-injurious behaviors were absent, but mood and impulsivity were not as improved as in thalamic stimulation. One month after stimulation was stopped (sham stimulation), tics progressively returned and became as severe as before surgery. Within 12 hours of combined thalamic and pallidal stimulation, the patient ceased self-injurious behaviors; final assessment revealed a $70 \%$ reduction in tics. Two years following the end of blinded conditions, tics and self-injurious behaviors remained significantly improved.

A similar randomized, controlled, double-blind crossover study was published by Welter et al. ${ }^{62}$ in 2008. Three patients with TS received DBS with trajectory mimicking that of Houeto et al. ${ }^{23}$ Patients were then randomized into 1 of 4 conditions (thalamic stimulation, pallidal stimulation, thalamic and pallidal stimulation, and no [sham] stimulation) for 2 months each. Bilateral pallidal stimulation resulted in a $65 \%, 96 \%$, and $74 \%$ reduc- tion in tic severity in Patients 1, 2, and 3, respectively. Bilateral thalamic stimulation resulted in a 64\%, 30\%, and $40 \%$ reduction in tic severity in Patients 1,2 , and 3 , respectively. Combined stimulation showed no added benefit, with a reported $60 \%, 43 \%$, and $76 \%$ reduction in tic severity in Patients 1, 2, and 3, respectively. In the sham condition, patients experienced an increase in tic severity compared with when stimulation was on. Long-term benefits continued in Patients 1 and 3 with combined thalamic and pallidal stimulation and in Patient 2 with solely pallidal stimulation.

Shahed et al. ${ }^{54}$ published a case report of a 16 -yearold male with severe, intractable TS, ADHD, OCD, self-injurious behaviors, anxiety, and depression. Due to marked functional and academic impairment, severe comorbidity, and lack of response to conventional treatment, the patient received bilateral DBS of the posteroventral $\mathrm{GPi}$, despite his young age. At the 6-month follow-up, an $84 \%$ tic reduction was reported, with improvement in comorbidities and quality of life.

In 2008, Dehning et al. ${ }^{14}$ described the effects of bilateral stimulation of the posteroventral GPi in a 44-yearold woman with worsening treatment-refractory TS, self-mutilating behaviors, and compulsions. During a 12-month follow-up period, the patient experienced full remission of tics. Reported side effects included depression, vertigo, and stomach aches. The authors later reported on 3 other patients who received bilateral DBS of the posteroventral Gpi. ${ }^{13}$ At 12 months after surgery, 1 patient experienced a $64 \%$ reduction in tics. However, the other 2 patients experienced no benefit from DBS and stimulation was eventually stopped.

A larger cohort of 5 patients was evaluated by Martínez-Fernández et al. ${ }^{36}$ Three patients underwent bilat- 


\section{J. Rotsides and A. Mammis}

eral DBS of the posteroventral GPi and 2 patients received bilateral stimulation of the anteromedial GPi. One of the patients in the posteroventral GPi group experienced worsening tics after 18 months of stimulation, so electrodes were repositioned to the anteromedial GPi. One year following the second surgery, this patient had a marked decrease in motor and vocal tics. Follow-up in the other patients ranged from 3 to 24 months. A mean $29 \%$ reduction in tic severity was observed, along with a $26 \%$ decrease in obsessive-compulsive symptoms and 54.4\% improvement in reported quality of life.

More recently, Cannon et al. ${ }^{9}$ reported on bilateral DBS of the anteromedial GPi in 11 patients with disabling, treatment-refractory TS. The authors assessed the effect of DBS on tic severity, obsessive-compulsive behaviors, depression, quality of life, and global functioning. One patient reported an increase in tics and adverse side effects, so the stimulator was switched off after 3 months. The other 10 patients reported a decrease in the number, severity, frequency, and intensity of tics. Final follow-up ranged from 4 to 30 months (mean 14 months) among patients. Motor and vocal tics were reduced by a mean $53 \%$ and $62 \%$, respectively. Total tic severity decreased by $49.6 \%$. The 9 patients who experienced obsessivecompulsive symptoms prior to surgery reported a mean $59 \%$ decrease in symptoms at final follow-up. There was a significant improvement in quality of life and global functioning, as well as a significant (74\%) reduction in depressive symptoms. Besides the 1 patient, no adverse side effects were reported. Three patients experienced hardware malfunctions, with worsening tics when stimulation was not present. One patient developed an infection and 2 patients reported feelings of anxiety.

There have also been reports of DBS targeting the GPe. In 2013, Piedimonte et al..$^{44}$ implanted electrodes bilaterally at the GPe in a 47-year-old patient with disabling, intractable TS. At the 3-month follow-up, the patient showed a 57.5\% improvement in tic severity, 50\% improvement in anxiety symptoms, 58.8\% improvement in depressive symptoms, and $36.4 \%$ improvement in global functioning. At the 6-month follow-up, tic severity, anxiety, and depression were improved by $70.5 \%, 75 \%$, and $82.3 \%$, respectively. Global functioning remained stable. Two years following surgery, the battery life was exhausted and could not be replaced due to financial reasons. Without stimulation, symptoms returned and a reduction in therapeutic effect was observed.

\section{Anterior Limb of the Internal Capsule/Nucleus Accumbens}

In 2005, Flaherty et al. ${ }^{17}$ published a case report of a 37-year-old patient with severe treatment-refractory TS, OCD, ADHD, and depression who received bilateral DBS of the ALIC-NA (Table 3). This trajectory was chosen based on the relative success in using DBS at this location to treat OCD. ${ }^{42}$ After 18 months, global tic severity had decreased by $20 \%$.

In 2007, Kuhn et al. ${ }^{29}$ described a patient with treatment-refractory TS and severe OCD who underwent bilateral stimulation of the ALIC-NA. A 40\%-50\% reduction in tic severity was observed at 2.5 years after surgery. Self-injurious behaviors and OCD symptoms were also significantly reduced. In the following year, Zabek et al. ${ }^{63}$ reported on the 28-month follow-up of unilateral DBS of the right NA in a single patient with severe intractable TS, self-injurious behaviors, and compulsions. At followup, there was a significant reduction in tics, self-injurious behavior, and compulsions. The total number of tics decreased from 236 to 48 .

Long-term follow-up in a patient who received bilateral DBS of the ALIC-NA was reported by Neuner et al. ${ }^{41}$ At 36 months after surgery, there was a $44 \%$ reduction in tic severity. Self-injurious behavior had ceased and OCD symptoms were markedly decreased. More recently, Sachdev et al. ${ }^{49}$ described a 42 -year-old patient with TS and "incapacitating" OCD who failed to respond to standard pharmacological and psychobehavioral therapies. The authors opted for DBS of the NA because OCD symptoms were the most debilitating. At the 1-month follow-up, a 57\% improvement in tic severity and $90 \%$ improvement in OCD symptoms were reported. These benefits were sustained at the 7-month follow-up, with further improvement in tic severity.

\section{Subthalamic Nucleus}

In 2009, Martinez-Torres et al. ${ }^{37}$ performed bilateral DBS of the subthalamic nucleus in a 38-year-old patient with TS and Parkinson's disease (PD) (Table 3). Tics began at the age of 7 and improved by the age of 12 . However, tics increased during adulthood, prior to the diagnosis of PD. No medication for tics was ever prescribed. The subthalamic nucleus was chosen because it is commonly targeted in DBS for PD. ${ }^{24}$ One year after surgery, there was a 57\% improvement in motor symptoms of PD and $97 \%$ decrease in tic frequency. While DBS was performed mainly to treat symptoms of PD, the significant reduction in tic frequency observed suggests that the subthalamic nucleus could be a potential target for DBS in treating TS in the future.

\section{Discussion}

Tourette's syndrome is characterized by variable clinical phenotypes and the level of severity and impairment differs among patients. In most cases, TS is selflimiting, but for a small percentage of patients tics persist in adulthood and conventional treatments prove ineffective. For these patients, DBS has been shown to be an effective and promising treatment option.

Most of the literature available regarding DBS for TS is case reports or small case series focusing on the use of a single target. The study by Servello et al..$^{53}$ allows for examination of a much larger cohort of patients, as well as comparison between multiple target sites. The primary target used by the authors was the medial thalamus (CM-Pf-Voi). Evidence suggests that a dysfunction of striatal-thalamic-cortical circuits plays an underlying role in the generation of tics. ${ }^{19}$ Inputs of the CM-Pf complex to the striatum modulate sensorimotor and limbic circuitry and DBS of this target may suppress excitatory feedback to motor and limbic parts of the striatum involved in the production of tics. ${ }^{50}$ In the same study, ${ }^{53}$ DBS of the posteroventral GPi was performed to address dystonic tics 
Deep brain stimulation for Tourette's syndrome

TABLE 3: Other DBS targets for TS

\begin{tabular}{|c|c|c|c|c|}
\hline Authors \& Year & No. of Patients & Target & Follow-Up & Outcomes \\
\hline Flaherty et al., 2005 & 1 & ALIC-NA & $18 \mathrm{mos}$ & $20 \%$ decrease in global tic severity \\
\hline Kuhn et al., 2007 & 1 & ALIC-NA & $2.5 \mathrm{yrs}$ & $40 \%-50 \%$ tic reduction \\
\hline Zabek et al., 2008 & 1 & unilateral right NA & $28 \mathrm{mos}$ & total no. of tics reduced from 236 to 48 \\
\hline Shields et al., 2008 & 1 & ALIC-NA (later revised to thalamus) & $18 \mathrm{mos}$ & $\begin{array}{l}21 \% \text { reduction in tics, } 25 \% \text { improvement in } \\
\text { overall impairment }\end{array}$ \\
\hline Neuner et al., 2009 & 1 & ALIC-NA & $36 \mathrm{mos}$ & $44 \%$ tic reduction \\
\hline Martinez-Torres et al., 2009 & 1 & subthalamic nucleus & $1 \mathrm{yr}$ & $97 \%$ decrease in tic frequency \\
\hline Sachdev et al., 2012 & 1 & NA & $7 \mathrm{mos}$ & $\begin{array}{l}\text { score reductions: } \\
63 \text { to } 13 \text { (YGTSS) } \\
39 \text { to } 6 \text { (YBOCS) }\end{array}$ \\
\hline
\end{tabular}

in 1 patient based on reported benefits of DBS for dystonia. ${ }^{34}$ The execution of tics in TS is believed to be caused by overactivity of striatal neurons that cause altered output to the GPi and substantia nigra pars reticulata. ${ }^{39}$ Thus, targeting the GPi in DBS may counteract overactive striatal output in patients with TS.

Interestingly, Servello et al. ${ }^{53}$ also performed a second "rescue surgery" targeting the ALIC-NA in a number of patients who continued to experience impairment from other comorbidities. This was performed on the basis that DBS of the ALIC-NA has been shown to successfully treat patients with OCD. ${ }^{20}$ As behavioral comorbidities may have a greater impact on functioning and quality of life than tics, this target may be a better choice in such TS patients. Furthermore, the ALIC contains extensive frontothalamic and frontostriatal projections and stimulation of this area may provide a beneficial effect in TS patients by influencing striatal-thalamic-cortical circuitry. ${ }^{17}$

Studies comparing the use of 1 target over another remain sparse and have produced contradictory results. A within-subject comparison ${ }^{55}$ revealed greater tic reduction and fewer side effects with stimulation at the medial thalamus versus the ALIC-NA, suggesting the medial thalamus as the preferable target for DBS in treating TS. Houeto et al. ${ }^{23}$ found similar improvements in tic severity following stimulation of the GPi, thalamus, or both. However, thalamic stimulation was shown to have a greater effect on the improvement of mood symptoms. On the other hand, Welter et al. ${ }^{62}$ reported the greatest tic reduction upon stimulation of the GPi compared with the medial thalamus, with no added benefit from combined stimulation. Clearly, more research is needed to replicate these results and sort out contradictory findings.

Further controversy in the treatment of TS with DBS arises when determining stimulation parameters following surgery. No definitive guidelines for programming exist and are largely based on trial and error. Optimal settings vary largely from patient to patient. In the available literature, optimal stimulation parameters for DBS of the medial thalamus revealed amplitudes ranging from 1.5 to $8.5 \mathrm{~V}$, pulse widths between 60 and $210 \mu \mathrm{s}$, and frequencies of $60-185 \mathrm{~Hz} .1,2,4,26,33,51-53,55$ Parameters for pallidal stimulation that afforded the best results ranged from 1 to $5 \mathrm{~V}, 60$ to $300 \mu \mathrm{s}$, and 20 to $185 \mathrm{~Hz} .^{9,13-15,36,54,59}$ For stimulation of the ALIC-NA, optimal parameters ranged from 3 to $7 \mathrm{~V}, 60$ to $210 \mu \mathrm{s}$, and 130 to $185 \mathrm{~Hz} \cdot$. $^{17,29,41,49,63}$ Alterations to stimulation parameters are made at the discretion of the surgeon and are largely based upon how the individual patient responds clinically.

Deep brain stimulation holds promise for the treatment of TS. The medial thalamus is the most widely used target, but increasing evidence supports the use of the GPi and ALIC-NA as well. The lack of randomized, controlled trials makes definitive conclusions about the relative efficacy of one target over another impossible. While future research is warranted, the small number of patients with intractable TS limits the ability to conduct such studies. Future research should aim to include larger sample sizes and employ standardized methods of evaluation, surgical techniques, outcome measurements, and follow-up periods.

\section{Disclosure}

The authors report no conflict of interest concerning the materials or methods used in this study or the findings specified in this paper.

Author contributions to the study and manuscript preparation include the following. Conception and design: Mammis. Acquisition of data: Rotsides. Analysis and interpretation of data: Rotsides. Drafting the article: Rotsides. Critically revising the article: Mammis. Reviewed submitted version of manuscript: both authors. Approved the final version of the manuscript on behalf of both authors: Mammis. Administrative/technical/material support: Mammis. Study supervision: Mammis.

\section{References}

1. Ackermans L, Duits A, Temel Y, Winogrodzka A, Peeters F, Beuls EA, et al: Long-term outcome of thalamic deep brain stimulation in two patients with Tourette syndrome. J Neurol Neurosurg Psychiatry 81:1068-1072, 2010

2. Ackermans L, Duits A, van der Linden C, Tijssen M, Schruers $\mathrm{K}$, Temel Y, et al: Double-blind clinical trial of thalamic stimulation in patients with Tourette syndrome. Brain 134:832844, 2011

3. American Psychiatric Association: Diagnostic and Statistical Manual of Psychiatry, ed 4. Washington, DC: American Psychiatric Association, 2000, pp 108-116

4. Bajwa RJ, de Lotbinière AJ, King RA, Jabbari B, Quatrano S, Kunze K, et al: Deep brain stimulation in Tourette's syndrome. Mov Disord 22:1346-1350, 2007

5. Baker EFW: Gilles de la Tourette syndrome treated by bimedial leucotomy. Can Med Assoc J 86:746-747, 1962 
6. Beck AT, Ward CH, Mendelson M, Mock J, Erbaugh J: An inventory for measuring depression. Arch Gen Psychiatry 4: 561-571, 1961

7. Bloch MH, Panza KE, Landeros-Weisenberger A, Leckman JF: Meta-analysis: treatment of attention-deficit/hyperactivity disorder in children with comorbid tic disorders. J Am Acad Child Adolesc Psychiatry 48:884-893, 2009

8. Burd L, Kerbeshian PJ, Barth A, Klug MG, Avery PK, Benz B: Long-term follow-up of an epidemiologically defined cohort of patients with Tourette syndrome. J Child Neurol 16:431437, 2001

9. Cannon E, Silburn P, Coyne T, O’Maley K, Crawford JD, Sachdev PS: Deep brain stimulation of anteromedial globus pallidus interna for severe Tourette's syndrome. Am J Psychiatry 169:860-866, 2012

10. Cavanna AE, Servo S, Monaco F, Robertson MM: The behavioral spectrum of Gilles de la Tourette syndrome. J Neuropsychiatry Clin Neurosci 21:13-23, 2009

11. Cheung MY, Shahed J, Jankovic J: Malignant Tourette syndrome. Mov Disord 22:1743-1750, 2007

12. Conelea CA, Woods DW, Zinner SH, Budman C, Murphy T, Scahill LD, et al: Exploring the impact of chronic tic disorders on youth: results from the Tourette Syndrome Impact Survey. Child Psychiatry Hum Dev 42:219-242, 2011

13. Dehning S, Feddersen B, Cerovecki A, Bötzel K, Müller N, Mehrkens JH: Globus pallidus internus-deep brain stimulation in Tourette's syndrome: can clinical symptoms predict response? Mov Disord 26:2440-2441, 2011

14. Dehning S, Mehrkens JH, Müller N, Bötzel K: Therapy-refractory Tourette syndrome: beneficial outcome with globus pallidus internus deep brain stimulation. Mov Disord 23:13001302, 2008

15. Diederich NJ, Kalteis K, Stamenkovic M, Pieri V, Alesch F: Efficient internal pallidal stimulation in Gilles de la Tourette syndrome: a case report. Mov Disord 20:1496-1499, 2005

16. Eddy CM, Cavanna AE, Gulisano M, Agodi A, Barchitta M, Calì $\mathrm{P}$, et al: Clinical correlates of quality of life in Tourette syndrome. Mov Disord 26:735-738, 2011

17. Flaherty AW, Williams ZM, Amirnovin R, Kasper E, Rauch SL, Cosgrove GR, et al: Deep brain stimulation of the anterior internal capsule for the treatment of Tourette syndrome: technical case report. Neurosurgery 57 (4 Suppl):E403, 2005

18. Freeman RD, Connolly JE, Baird PA: Tourette's syndrome: update. Can Med Assoc J 130:1554-1557, 1984

19. Galvez-Jimenez N: Tics and Tourette syndrome: an adult perspective. Cleve Clin J Med 79 (Suppl 2):S35-S39, 2012

20. Goodman WK, Alterman RL: Deep brain stimulation for intractable psychiatric disorders. Annu Rev Med 63:511-524, 2012

21. Hassan N, Cavanna AE: The prognosis of Tourette syndrome: implications for clinical practice. Funct Neurol 27:23-27, 2012

22. Hassler R, Dieckmann G: [Stereotaxic treatment of tics and inarticulate cries or coprolalia considered as motor obsessional phenomena in Gilles de la Tourette's disease.] Rev Neurol (Paris) 123:89-100, 1970 (Fr)

23. Houeto JL, Karachi C, Mallet L, Pillon B, Yelnik J, Mesnage $\mathrm{V}$, et al: Tourette's syndrome and deep brain stimulation. J Neurol Neurosurg Psychiatry 76:992-995, 2005

24. Humphries MD, Gurney K: Network effects of subthalamic deep brain stimulation drive a unique mixture of responses in basal ganglia output. Eur J Neurosci 36:2240-2251, 2012

25. Jankovic J, Kurlan R: Tourette syndrome: evolving concepts. Mov Disord 26:1149-1156, 2011

26. Kaido T, Otsuki T, Kaneko Y, Takahashi A, Omori M, Okamoto T: Deep brain stimulation for Tourette syndrome: a prospective pilot study in Japan. Neuromodulation 14:123-129, 2011

27. Kendall PC, Finch AJ Jr, Auerbach SM, Hooke JF, Mikulka PJ: The State-Trait Anxiety Inventory: a systematic evaluation. J Consult Clin Psychol 44:406-412, 1976
28. Knight T, Steeves T, Day L, Lowerison M, Jette N, Pringsheim T: Prevalence of tic disorders: a systematic review and metaanalysis. Pediatr Neurol 47:77-90, 2012

29. Kuhn J, Lenartz D, Mai JK, Huff W, Lee SH, Koulousakis A, et al: Deep brain stimulation of the nucleus accumbens and the internal capsule in therapeutically refractory Tourettesyndrome. J Neurol 254:963-965, 2007

30. Lajonchere C, Nortz M, Finger S: Gilles de la Tourette and the discovery of Tourette syndrome. Includes a translation of his 1884 article. Arch Neurol 53:567-574, 1996

31. Leckman JF, Bloch MH, Scahill L, King RA: Tourette syndrome: the self under siege. J Child Neurol 21:642-649, 2006

32. Leckman JF, Riddle MA, Hardin MT, Ort SI, Swartz KL, Stevenson J, et al: The Yale Global Tic Severity Scale: initial testing of a clinician-rated scale of tic severity. J Am Acad Child Adolesc Psychiatry 28:566-573, 1989

33. Lee MW, Au-Yeung MM, Hung KN, Wong CK: Deep brain stimulation in a Chinese Tourette's syndrome patient. Hong Kong Med J 17:147-150, 2011

34. Lyons MK: Deep brain stimulation: current and future clinical applications. Mayo Clin Proc 86:662-672, 2011

35. Maciunas RJ, Maddux BN, Riley DE, Whitney CM, Schoenberg MR, Ogrocki PJ, et al: Prospective randomized doubleblind trial of bilateral thalamic deep brain stimulation in adults with Tourette syndrome. J Neurosurg 107:1004-1014, 2007

36. Martínez-Fernández R, Zrinzo L, Aviles-Olmos I, Hariz M, Martinez-Torres I, Joyce E, et al: Deep brain stimulation for Gilles de la Tourette syndrome: a case series targeting subregions of the globus pallidus internus. Mov Disord 26:19221930, 2011

37. Martinez-Torres I, Hariz MI, Zrinzo L, Foltynie T, Limousin P: Improvement of tics after subthalamic nucleus deep brain stimulation. Neurology 72:1787-1789, 2009

38. McNaught KS, Mink JW: Advances in understanding and treatment of Tourette syndrome. Nat Rev Neurol 7:667-676, 2011

39. Mink JW: The basal ganglia and involuntary movements: impaired inhibition of competing motor patterns. Arch Neurol 60:1365-1368, 2003

40. Mink JW: Basal ganglia dysfunction in Tourette's syndrome: a new hypothesis. Pediatr Neurol 25:190-198, 2001

41. Neuner I, Podoll K, Lenartz D, Sturm V, Schneider F: Deep brain stimulation in the nucleus accumbens for intractable Tourette's syndrome: follow-up report of 36 months. Biol Psychiatry 65:e5-e6, 2009

42. Nuttin BJ, Gabriëls LA, Cosyns PR, Meyerson BA, Andréewitch S, Sunaert SG, et al: Long-term electrical capsular stimulation in patients with obsessive-compulsive disorder. Neurosurgery 52:1263-1274, 2003

43. Pappert EJ, Goetz CG, Louis ED, Blasucci L, Leurgans S: Objective assessments of longitudinal outcome in Gilles de la Tourette's syndrome. Neurology 61:936-940, 2003

44. Piedimonte F, Andreani JC, Piedimonte L, Graff P, Bacaro V, Micheli F, et al: Behavioral and motor improvement after deep brain stimulation of the globus pallidus externus in a case of Tourette's syndrome. Neuromodulation 16:55-58, 2013

45. Porta M, Brambilla A, Cavanna AE, Servello D, Sassi M, Rickards H, et al: Thalamic deep brain stimulation for treatment-refractory Tourette syndrome: two-year outcome. Neurology 73:1375-1380, 2009

46. Pullen SJ, Wall CA, Lee KH, Stead SM, Klassen BT, Brown TM: Neuropsychiatric outcome of an adolescent who received deep brain stimulation for Tourette's syndrome. Case Rep Neurol Med 2011:209467, 2011

47. Robertson MM: Tourette syndrome, associated conditions and the complexities of treatment. Brain 123:425-462, 2000

48. Rosario-Campos MC, Miguel EC, Quatrano S, Chacon P, Ferrao Y, Findley D, et al: The Dimensional Yale-Brown Ob- 


\section{Deep brain stimulation for Tourette's syndrome}

sessive-Compulsive Scale (DY-BOCS): an instrument for assessing obsessive-compulsive symptom dimensions. Mol Psychiatry 11:495-504, 2006

49. Sachdev PS, Cannon E, Coyne T, Silburn P: Bilateral deep brain stimulation of the nucleus accumbens for comorbid obsessive compulsive disorder and Tourette's syndrome. BMJ Case Rep 2012:bcr2012006579, 2012

50. Sadikot AF, Rymar VV: The primate centromedian-parafascicular complex: anatomical organization with a note on neuromodulation. Brain Res Bull 78:122-130, 2009

51. Savica R, Stead M, Mack KJ, Lee KH, Klassen BT: Deep brain stimulation in Tourette syndrome: a description of 3 patients with excellent outcome. Mayo Clin Proc 87:59-62, 2012

52. Servello D, Porta M, Sassi M, Brambilla A, Robertson MM: Deep brain stimulation in 18 patients with severe Gilles de la Tourette syndrome refractory to treatment: the surgery and stimulation. J Neurol Neurosurg Psychiatry 79:136-142, 2008

53. Servello D, Sassi M, Brambilla A, Defendi S, Porta M: Longterm, post-deep brain stimulation management of a series of 36 patients affected with refractory Gilles de la Tourette syndrome. Neuromodulation 13:187-194, 2010

54. Shahed J, Poysky J, Kenney C, Simpson R, Jankovic J: GPi deep brain stimulation for Tourette syndrome improves tics and psychiatric comorbidities. Neurology 68:159-160, 2007

55. Shields DC, Cheng ML, Flaherty AW, Gale JT, Eskandar EN: Microelectrode-guided deep brain stimulation for Tourette syndrome: within-subject comparison of different stimulation sites. Stereotact Funct Neurosurg 86:87-91, 2008

56. Singer HS: Treatment of tics and tourette syndrome. Curr Treat Options Neurol 12:539-561, 2010

57. Swain JE, Leckman JF: Tourette syndrome and tic disorders: overview and practical guide to diagnosis and treatment. Psychiatry (Edgmont) 2:26-36, 2005
58. Temel Y, Visser-Vandewalle V: Surgery in Tourette syndrome. Mov Disord 19:3-14, 2004

59. Van der Linden C, Colle H, Vandewalle V, Alessi G, Rijckaert D, De Waele L: Successful treatment of tics with bilateral internal pallidum (Gpi) stimulation in a 27-year old male patient with Gilles de la Tourette's syndrome. Mov Disord 17 (5 Suppl):S341, 2002

60. Vandewalle V, van der Linden C, Groenewegen HJ, Caemaert J: Stereotactic treatment of Gilles de la Tourette syndrome by high frequency stimulation of thalamus. Lancet 353:724, 1999

61. Visser-Vandewalle V, Temel Y, Boon P, Vreeling F, Colle H, Hoogland G, et al: Chronic bilateral thalamic stimulation: a new therapeutic approach in intractable Tourette syndrome. Report of three cases. J Neurosurg 99:1094-1100, 2003

62. Welter ML, Mallet L, Houeto JL, Karachi C, Czernecki V, Cornu $\mathrm{P}$, et al: Internal pallidal and thalamic stimulation in patients with Tourette syndrome. Arch Neurol 65:952-957, 2008

63. Zabek M, Sobstyl M, Koziara H, Dzierzecki S: Deep brain stimulation of the right nucleus accumbens in a patient with Tourette syndrome. Case report. Neurol Neurochir Pol 42: 554-559, 2008

Manuscript submitted July 14, 2013.

Accepted August 14, 2013.

Please include this information when citing this paper: DOI: 10.3171/2013.8.FOCUS13292.

Address correspondence to: Antonios Mammis, M.D., Neurological Surgery, Rutgers New Jersey Medical School, 90 Bergen St., Ste. 8100, Newark, NJ 07103. email: antonios.mammis@ rutgers.edu. 